\title{
Development of an Innovative Method for Combating Blood-Sucking Diptera insects
}

\section{Sergei Engashev ${ }^{1}$, Aleksey Mironenko ${ }^{1}$, Fedor Vasilevich ${ }^{1}$, Alexander Deltsov $^{1}$, and Ekaterina Engasheva ${ }^{2}$}

${ }^{1}$ Moscow State Academy of Veterinary Medicine and Biotechnology - MVA named after K.I. Skryabin", Moscow, Russia

${ }^{2}$ All-Russian Research Institute of Veterinary Sanitation, Hygiene, and Ecology, Moscow, Russia

ORCID:

Sergei Engashev: http://orcid.org/0000-0002-9701-3822

\section{Abstract}

This article describes an innovative method for regulating populations of blood-sucking Diptera that parasitize cows. This relates to the field of agriculture, namely to the means of protecting farm animals from insect bites, and can be used to protect farm animals from ectoparasites during the period of their grazing. To produce these products, the polymer was treated with an impregnating solution containing pyrethroid $(2-26 \%$

Corresponding Author: Aleksey Mironenko mironenko.a@vetmag.ru

Published: 5 April 2021

Publishing services provided by Knowledge E

(c) Sergei Engashev et al. This article is distributed under the terms of the Creative Commons Attribution License, which permits unrestricted use and redistribution provided that the original author and source are credited.

Selection and Peer-review under the responsibility of the DonAgro Conference Committee.

\section{G OPEN ACCESS} by weight of the untreated polymer product), an inhibitor of arthropod detoxification enzyme systems (0.5-20.0\%), a lubricant (0.1-3.0\%) and an aliphatic ketone (5-90\%). The method was simple in execution, and the insecticidal acaricidal polymer products obtained according to the method had a long shelf life of at least seven months. The products were resistant to environmental influences and did not lead to environmental pollution with excess active substances.

Keywords: Ear tags, s-fenvalerate, piperonyl butoxide, Diptera.

\section{Introduction}

The Blood-sucking dipterans (mosquitoes, midges, biting midges, gadflies, horse flies and face flies) are widespread and numerous in various natural and climatic zones of the European part of the Russian Federation $[1,2]$. This is due to favorable climatic conditions, the abundance of breeding sites for blood-sucking dipterans, as well as a high concentration of livestock complexes specializing in dairy farming in the region under study [3].

Being mechanical and biological carriers of many pathogens of infectious and invasive diseases (anaplasmosis, brucellosis, moraxellosis, thelaziosis, ehrlichiosis, viral keratoconjunctivitis, tularemia, etc.), they can cause anemia and stress in highly productive animals and young animals [4-6]. 
The economic damage from parasitizing dipterans on cattle, due to reduced productivity, stress, and culling of animals from the herd, significantly exceeds the losses caused by infectious diseases, and is measured in hundreds of millions of rubles a year $[2,7]$.

Currently, the protection of cattle from ectoparasites is carried out using multiple treatments of the skin and hair of animals with solutions of insecticides and repellents [8].

However, this method contains a number of disadvantages, which include: the laboriousness of carrying out protective measures that require special equipment, as well as the construction of special corrals for livestock, the uneconomical consumption of insecticidal and repellent solutions during application to the skin of an animal, leads to an undesirable accumulation of active substances in the body. animals and environmental pollution $[3,7,9]$.

The drugs existing on the market from the group of organophosphorus compounds and carbamates, used for the purpose of multiple treatments of dairy cattle from bloodsucking dipterans, are ineffective in the spring-summer and early autumn periods, are economically unfeasible and require improvement [10].

1. Prospects for the use in veterinary medicine of individual polymer ear tags impregnated with synthetic pyrethroids for cattle completely replace repeated treatments of animals with repellents and insecticides and allow long-term control of ectoparasite populations with minimal financial and labor costs). The use of preparations in the form of individual polymer products contributes to the preservation of dairy and meat productivity of animals, does not pollute the environment and minimizes the contact of veterinarians, thereby reducing the level of stress received in the process of constant treatments[11, 12].

The use of insecticides in veterinary medicine can significantly reduce the population of blood-sucking insects, thereby bypassing the risk of transmission of diseases to animals and humans. However, the frequent use of insecticides of various chemical groups (organochlorine compounds, organophosphorus compounds, carbamates, pyrethroids) leads to environmental pollution and the emergence of resistant insect populations $[7,13]$. According to numerous research results, synthetic pyrethroids, which are effective at low doses, have high insecticidal activity and repellent properties for dipterans, turned out to be the most promising for treating animals against gnats and flies. Low toxicity for warm-blooded animals and the duration of action puts synthetic pyrethroids in no competition with other groups of chemicals for treating cattle $[4,9,14]$. 
Constant control of populations of blood-sucking dipterans with the help of individual ear tags and tail tapes is more economically profitable than using a large amount of toxic insecticidal solutions for the same purpose, and the successful testing of the new principle of livestock protection entailed the further development of methods for its implementation, as well as the determination of the most effective fillers and their concentrations $[2,15]$.

In this regard, alternative methods of livestock protection are being developed, which allow for a long-term control of the populations of blood-sucking dipterans and zoophilous flies with minimal labor and treatment and prophylactic costs All of them are based on the principle of individual long-term protection, which consists in the use of various kinds of devices, attached in one way or another to the animal and consisting of a solid filler in which a substance of substances highly toxic to insects (insecticides), but safe for animals, is homogeneously distributed $[16,11,14]$

The practical implementation of this principle was first undertaken in 1970 to protect cattle from the small cow burner Haematobia irritans. By putting wax bars containing crotoxifos on $23-33 \%$ of the heads in a herd, they were able to achieve satisfactory protection of the entire herd within a week. and when using resin collars impregnated with dichlorvos, bars on neck chains and ear tags, $100 \%$ control of flares was achieved for a week or a month [17].

There are various forms of livestock protection, but one of the most effective, allowing to control populations of ectoparasites with minimal labor and drug costs, is the use of polymer products made from a filler stuffed with an insecticide. The use of polymer products to protect animals from ectoparasites completely replaces repeated treatments of animals with repellents and insecticides, does not pollute the environment and contributes to the preservation of the productivity of farm animals $[8,16,18]$.

Gradually released from the surface of the polymer product, the active components are transferred to the skin and hair and are distributed throughout the animal's body. When insects come into contact with the scalp, the active components show their insecticidal effect, causing the death of dipterans attacking animals. The strong adhesion of the active components of the tag with the secretion of the sebaceous glands ensures their high resistance to atmospheric precipitation [19].

A known method of manufacturing insecticidal tags for farm animals, including placing a replaceable distribution element in the form of a porous container filled with an insecticidal composition, on a plastic tag (see, for example, WO 8503197, 1985). However, the technical resource of such an element is very small, and the assembly-disassembly of such an element on a plastic tag creates intractable problems [9, 15, 20, 21]. Closest to 
the claimed one is a method including mixing a solid polymeric organic macromolecular substance, a plasticizer and a pesticide, followed by the manufacture of insecticidal tags by injection molding (see, for example, US 4265876, 05.05.1981).

However, the known method is technologically complex, and the tags produced by the known method are quite fragile [22]. The task of the group of inventions is to improve the consumer qualities of an insecticidal polymer product while simplifying the method for its manufacture.

The study was to develop and study the effectiveness of using a prolonged-release drug in the form of an individual ear tag for the fight against blood-sucking dipterans $[1,23,24]$.

\section{Methods and Equipment}

Research on the development of the drug was carried out at the Department of Parasitology and Pharmacology on the basis of the Federal State Budgetary Educational Institution of Higher Professional Education "Moscow State Academy of Veterinary Medicine and Biotechnology - MVA named after M.V. K.I. Scriabin "and the Scientific Center "Agrovetzashchita" (LLC “AVZ animal health").

In the development of the drug, polymer tags were used, which are yellow plates in the form of a regular hexagon with rounded corners, while one of the vertices of the hexagon is made elongated, and a hole is made on it for fastening. Overall dimensions: $103.5 \mathrm{~mm}$ length, $78.1 \mathrm{~mm}$ width and $1.7 \mathrm{~mm}$ thickness, weight $11.55 \mathrm{~g}$. The tag is made by injection molding, made of Sh-51 polymer. The dielectric parameters of the polymer were measured at a frequency of $1 \mathrm{MHz}$ - dielectric constant $\varepsilon=3.1$, loss tangent tan $\alpha$ $=1.1 \cdot 10-2$.

Saturation limit testing was performed as follows. 1 liter of acetone (moisture $0.01 \%$ ) is placed in a beaker with a volume of 2 liters. A tag was hung on a fluoroplastic holder in such a way that it was completely immersed under the acetone layer, but did not touch the glass walls.

The saturation was determined by weighing at an interval of 10 minutes until the end of the weight change. 110 minutes after the start of saturation, the tag weight was 21.44 g, and then the weight did not change. Thus, a Sh-51 PVC tag with an initial weight of $11.51 \mathrm{~g}$ absorbed $9.93 \mathrm{~g}$ of acetone, which corresponds to $86.3 \%$ of the initial weight of the polymer product.

Impregnation of tags with active substances was carried out as follows. In a polyethylene barrel with a volume of 30 liters, equipped with a hermetically sealed lid, 50 tags 
were placed, with a total weight of $577.4 \mathrm{~g}, 83.0 \mathrm{~g}$ of S-fenvalerate $(14.4 \%$ of the weight of tags) and $100 \mathrm{~g}$ of piperonyl butoxide (17, 3\% of the weight of the tags), as well as $2.5 \mathrm{~g}$ of PEG-400 stearate as a lubricant (0.4\% of the weight of the tags) and $92 \mathrm{~g}$ of acetone ( $18.5 \%$ of the maximum amount of acetone absorbing this polymer).

The barrel was hermetically sealed and installed in a gravity mixer frame with an axis of rotation located at an angle of $45^{\circ}$ to the barrel axis (the device is known in the art as a "drunken barrel" mixer).

The shaft drive was equipped with an electric motor with a gearbox, while the electric motor was powered through a frequency converter, which made it possible to adjust the rotation speed from 5 to $60 \mathrm{rpm}$. The rotation speed was set to $10 \mathrm{rpm}$ and the impregnation process was carried out for 2 hours. After that, the barrel was removed from the frame, opened and the ear tags were dried in an open barrel at room temperature to constant weight - within 24 hours. After drying, the weight of the treated tags was $720 \mathrm{~g}$.

For the products obtained, the content of insecticidal-repellent components (Sfenvalerate and piperonyl butoxide) and the change in geometric dimensions and strength characteristics are determined.

The strength characteristics of the product and their changes during processing were determined as follows. The tag was secured from above and below with special flat clamps. A $7 \mathrm{~kg}$ weight was placed on the weighing platform, to which a lower clamp was attached. A hand hoist, placed on a movable arm, was fixed to the upper clamp. Using a reducer, the hoists slowly increase the load on the product until it breaks. At the moment of rupture, the difference between the initial weight of the load $(74.45 \mathrm{~kg})$ and the readings of the balance at the moment of rupture was recorded. Measurement of product strength (tensile strength) is calculated according to formula 1, change in product tensile strength - according to formula 2.

$$
F(H)=\left(m_{0}-m_{p}\right) \times 9.8,
$$

where:

$\mathrm{m}_{0}$ - indication of the balance before rupture, $\mathrm{kg}$;

$\mathrm{m}_{p}$ - indication of the balance at the moment of rupture, $\mathrm{kg}$;

9.8 - acceleration of gravity, $\mathrm{m} / \mathrm{s}$.

$$
\Delta F(\%)=\left(F_{1}-F_{0}\right) \times 100 / F_{0},
$$

where:

FO is the tensile strength of the product before impregnation, $\mathrm{N}$; 
$\mathrm{F} 1$ is the tensile strength of the processed dried product after.

The test results are shown in Table 1.

Testing of the ear tags obtained on flies (Musca domestica $L$.) is carried out as follows: the flies are released into the cages with tags and in containers with water. The number of insects in each cage is from 92 to 125 individuals. Observations are carried out daily and continuously - for 7-8 hours, the behavior of flies is noted. Dead flies are removed and counted as they appear. Room temperature $20-28^{\circ} \mathrm{C}$ and relative humidity from 50 to $70 \%$ correspond to the accepted conditions for conducting experiments with winged flies.

Testing the ear tags obtained on mosquitoes (Culicidae) is carried out as follows: the mosquitoes are released into the cages with tags and in containers with water. The number of insects in each cage is from 30 to 50 individuals. The observation is carried out continuously for 7-8 hours, the reaction of the mosquitoes is noted. Dead mosquitoes are removed as they appear and counted. Room temperature $23-28^{\circ} \mathrm{C}$ and relative humidity from 50 to $70 \%$ correspond to the accepted conditions for conducting experiments with winged mosquitoes.

The test of the obtained tags on the imago of a rat flea (Nosopsyllus fasciatus) is carried out as follows: the repellent effect is determined in a cylinder with a volume of 1 liter. Thirty adults of a rat flea are poured onto the bottom of the cylinder. Flea activity is determined (control option - coarse calico strip). The experimental variant is a strip of coarse calico $40 \mathrm{~cm}$. long, at a height of $15 \mathrm{~cm}$ from the bottom of the vessel. An area of $5 \mathrm{~cm}$ is treated with a means, then an untreated coarse calico.

The insecticidal effect is determined by the method of group replanting of fleas on tags. Contact time 5 and 10 minutes. Damage and mortality records - after 24 hours.

The coefficient of repellent action (CRA) is calculated by the formula (3):

$$
\mathrm{CRA}=\frac{\mathrm{A}-\mathrm{B}}{\mathrm{A}} \times 100 \%,
$$

where:

A - the number of fleas in the control for 15 minutes;

$B$ - the number of fleas in the experiment for 15 minutes;

100 - translation in \%.

The results of tests of the obtained tags on flies, mosquitoes, imago of a rat flea are presented in tables $2-5$. 
TABLE 1: Test results for polymer products (ear tags)

\begin{tabular}{l|c|c|}
\multicolumn{3}{c}{ Parameters before impregnation } \\
$\begin{array}{l}\text { Geometric } \\
\text { dimensions }\end{array}$ & $\begin{array}{c}\text { Average } \\
\text { weight } 10 \\
\text { grams }\end{array}$ & $\begin{array}{c}\text { F- tensile } \\
\text { strength, } H\end{array}$ \\
\hline $\begin{array}{l}\text { Length } 103.5 \\
\text { mm; Width }\end{array}$ & 11,55 & 472 \\
$\begin{array}{l}78.1 \mathrm{~mm} ; \\
\text { Thickness } \\
1.7 \mathrm{~mm} \text {. }\end{array}$ & & \\
\hline
\end{tabular}

\begin{tabular}{|c|c|c|c|c|c|}
\hline $\begin{array}{c}\text { Geometric } \\
\text { dimensions }\end{array}$ & $\begin{array}{c}\text { Average } \\
\text { weight 10 } \\
\text { grams }\end{array}$ & $\begin{array}{c}\text { S-Fenvalerate } \\
\text { content wt., \% }\end{array}$ & $\begin{array}{c}\text { Piperonyl } \\
\text { butoxide } \\
\text { content wt. \% }\end{array}$ & $\begin{array}{c}\text { F- tensile } \\
\text { strength, H }\end{array}$ & $\begin{array}{c}\text { Difference F- } \\
\text { tensile } \\
\text { strength, H }\end{array}$ \\
$\begin{array}{c}\text { Length 109.1 } \\
\text { mm; Width }\end{array}$ & 109,4 & 9,6 & 12,4 & 325 & $-31,1$ \\
\hline $\begin{array}{c}82.3 \text { mm; } \\
\text { Thickness } 1.8 \\
\text { mm. }\end{array}$ & & & & & \\
\end{tabular}

TABLE 2: The results of studying the effectiveness of action on flies (Musca domestica L.)

\begin{tabular}{|c|c|c|c|c|c|c|c|c|c|c|c|c|c|}
\hline \multicolumn{14}{|c|}{ The effectiveness of the drug against flies, \% } \\
\hline \multicolumn{2}{|c|}{ After 20 minutes } & \multicolumn{2}{|c|}{1 hour } & \multicolumn{2}{|c|}{2 hour } & \multicolumn{2}{|c|}{3 hour } & \multicolumn{2}{|c|}{4 hour } & \multicolumn{2}{|c|}{6 hour } & \multicolumn{2}{|c|}{24 hours } \\
\hline $\begin{array}{l}1 \text { Experi- } \\
\text { ence }\end{array}$ & $\begin{array}{l}2 \text { Experi- } \\
\text { ence }\end{array}$ & 1 & 2 & 1 & 2 & 1 & 2 & 1 & 2 & 1 & 2 & 1 & 2 \\
\hline 7,7 & 9,2 & 11,5 & 16,1 & 23,0 & 27,5 & 23,0 & 32,0 & 57,5 & 34,4 & 57,6 & 87,4 & 100 & 100 \\
\hline
\end{tabular}

\section{Results}

The tag has a pronounced insecticidal effect of protection against flies, causing $100 \%$ death of flies after 1 day. Thus, we have established the presence of an insecticidal action against flies.

TABLE 3: The results of studying the effectiveness of action on mosquitoes (Culicidae).

\begin{tabular}{|c|c|c|c|c|c|c|c|}
\hline \multicolumn{8}{|c|}{ The effectiveness of the drug against mosquitoes, \% } \\
\hline \multicolumn{2}{|c|}{ After 5 minutes } & \multicolumn{2}{|c|}{1 hour } & \multicolumn{2}{|c|}{2 hour } & \multicolumn{2}{|c|}{3 hour } \\
\hline No 1 experience & No 2 experience & No 1 & No 2 & No 1 & No 2 & No 1 & No 2 \\
\hline 38,0 & 37,5 & 100 & 100 & - & - & - & - \\
\hline
\end{tabular}

The tag showed a high insecticidal effect: the death of mosquitoes within the first hour from the beginning of the experiment was $100 \%$ in both experiments. Thus, the presence of insecticidal action of insecticidal tags on mosquitoes was established.

TABLE 4: The tests results on the adult rat flea
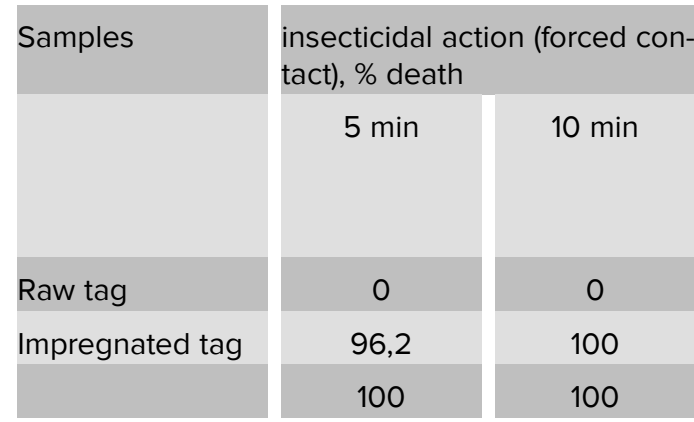

\begin{tabular}{|c|c|c|}
\hline \multicolumn{3}{|c|}{ insecticidal action (free contact), \% death } \\
\hline $\begin{array}{c}3 \text { insects } \\
\text { emerge from } \\
\text { an open } \\
\text { vessel, min }\end{array}$ & $\begin{array}{c}\text { coefficient of } \\
\text { repellent } \\
\text { action (CRA), } \\
\%\end{array}$ & Paralyzed, \% \\
\hline $3,75 \mathrm{~min}$ & & 0 \\
\hline No & 93,8 & 90 \\
\hline No & 86,7 & 90 \\
\hline
\end{tabular}

The insecticidal effect of the tag is achieved within 10 minutes - complete death of the imago of the rat flea is observed. Presence of a high repellent action of the tag on 
the imago of a rat flea was established, the coefficient of repellent action (CRA) for 15 minutes was $86.7-93.8 \%$, paralysis reaches $90 \%$.

\section{Discussion}

Despite the large amount of scientific data and publications on the effectiveness of using individual multi-dose containers with substances to combat blood-sucking Diptera in animal husbandry, ear tags are the most practical, easy to manufacture and use.

this form of the drug allows for long-term control over populations of blood-sucking insects, is less dangerous for the environment and does not act on insects that do not show interest in farm animals.

\section{Conclusion}

The ear tag has a high insecticidal effect: the death of flies within the first hour from the beginning of the experiment was $93.1 \%$ in the first experiment and $87.3 \%$ in the second. The death of mosquitoes within the first hour from the beginning of the experiment was $100 \%$ in both experiments.

The presence of a high repellent and insecticidal effect on the imago of a rat flea was established, the coefficient of repellent action (CRA) for 15 minutes was 86.7-93.8\%, paralysis reaches $90 \%$.

Thus, the presence of a pronounced insecticidal and repellent effect of tags on flies, mosquitoes and an imago rat flea was established.

The insecticidal effect of the drug is achieved within 10 minutes - complete death of imago insects is observed.

\section{Funding}

Research and development was carried out with the financial and scientific support of the «Research center Agrovetzashchita» and the pharmaceutical company «AVZ»Ltd, Russia. 


\section{Acknowledgement}

The authors would like to thank their colleague for their contribution and support to the research. They are also thankful to all the reviewers who gave their valuable inputs to the manuscript and helped in completing the paper.

\section{Conflict of Interest}

The authors have no conflict of interest to declare.

\section{References}

[1] Avila-Rodriguez, V., et al. (2015). Pupal Parasitoids (Hymenoptera: Pteromalidae) of Filth-Breeding Flies (Diptera: Muscidae) of Dairy Stables of Jalisco. Southwestern Entomologist, vol. 40, issue 1, pp. 141-149.

[2] Engashev, S. V., et al. (2019). Ear Tallies and Preparations in form Spot-On Flyblock and their Efficiency for Cattle. Veterinary Medicine Journal Veterinary, vol. 12, pp. 34-39.

[3] Denning, S. S., Washburn, S. P. and Watson, D. W. (2014). Development of a Novel Walk-Through Fly Trap for the Control of Horn Flies and other Pests on Pastured Dairy Cows. Journal of Dairy Science vol. 97, pp. 4624-4631. doi: https://doi.org/10. 3168/jds.2013-7872

[4] Adams, M. E. (1980). Neural and behavioral correlates of pyrethroid and DDTtype poisoning in the house fly, Musca domestica L. Pesticide Biochemistry and Physiology, vol. 13, pp. 137-147.

[5] Ahrens, E. H. and Gocke, J. (1979). Season Long Horn Fly Control with an Insecticide - Impregnated Ear Tag. Journal of Economic Entomology, vol. 72, pp. 214-215.

[6] Arena, A. C., et al. (2008). Fenvalerate, a Pyrethroid Insecticide, Adversely Affects Sperm Production and Storage in Male Rats. Journal of Toxicology and Environmental Health, Part A, vol. 71, issue 23, pp. 1550-1558.

[7] Novak, M. D. (2020). Dynamics of the Number of Horseflies and Zoophilous Flies in the Central Region of the Russian Federation. Veterinary Medicine Journal, vol. 6, pp. 28-32.

[8] Baldacchino, F., et al. (2013). Transmission of Pathogens by Stomoxys Flies (Diptera, Muscidae): a Review. Parasite,vol.20 pp. 20-26. doi.org/10.1051/parasite/2013026 
[9] Benelli, G. and Pavela, R. (2018). Beyond Mosquitoes - Essential Oil Toxicity and Repellency against Bloodsucking Insects. Industrial Crops and Products, vol. 117, pp. 382-392.

[10] Beresford, D. V. and Sutcliffe, J. E. (2008). Male Stable Fly (Stomoxys Calcitrans) Response to $\mathrm{CO}_{2}$ Changes with Age: Evidence from Wind Tunnel Experiments and Field Collections. Journal of Vector Ecology. vol. 33, issue 2, pp. 247-254.

[11] Beresford, D. V. and Sutcliffe, J. F. (2017). Evidence for Sticky Trap Avoidance by Stable Fly, Stomoxys Calcitrans (Diptera: Muscidae), in Response to Trapped Flies. Journal of the American Mosquito Control Association. vol. 33, issue 3, pp. 250-252.

[12] Burns, C. J. and Pastoor, T. P. (2018). Pyrethroid Epidemiology: A Quality-Based Review. Critical Reviews in Toxicology, vol. 48, issue 4, pp. 297-311.

[13] Weeks, E. N. I., et al. (2017) Effects of Four Commercial Fungal Formulations on Mortality and Sporulation in House Flies (Musca Domestica) and Stable Flies (Stomoxys Calcitrans). Medical and Veterinary Entomology, vol. 31, issue 1, pp. 1522.

[14] Harvey, T. L. and Brethour, J. R. (1983). Controlling Horn Fly (Diptera; Muscidae) in Cow-Calf Herds with Insecticide-Impregnated Ear Tag Treatments of Nursing Calves. Journal of Economic Entomology, vol. 76, pp. 117-118.

[15] Elliot, S. and Krafsur, R. D. (1997). Bionomics of the Face Fly, Musca Autumnalis. Annual Review of Entomology, vol. 2, pp. 503-523.

[16] Esaulova, N. V., et al. (2018). Flyblock Insecticidal Tags - A Reliable Way to Protect Cattle from Bloodsucking Insects and Ixodic Ticks. Journal of Dairy and Beef Cattle Farming, vol. 3, pp. 29-33.

[17] Wang, J., et al. (2012). The Insecticide Synergist Piperonyl Butoxide Inhibits Hedgehog Signaling: Assessing Chemical Risks. Toxicological Sciences: An Official Journal of the Society of Toxicology, vol. 128, issue 2, pp. 517-523.

[18] Esaulova, N. V. (2020). About Long-Term Protection of Cattle from Blood-Sucking Insects and Ixodid Ticks. Journal Veterinary of Agricultural Animals, vol. 4, pp. 5561.

[19] Miller, J. A., et al. (1981). Larvicidal activity of Merck MK-933, an Avermectin, against the Horn Fly, Stable Fly, Face Fly, and House Fly. Journal of Economic Entomology, vol. 74, pp. 608-611.

[20] Teskey, H. J. (1990). The Horse Flies and Deer Flies of Canada and Alaska (Diptera: Tabanidae). Agriculture Canada, vol. 2, pp. 380-381. 
[21] Mironenko, A. V. (2020). Clinical Trials of the Medicinal Product for Veterinary Use "FLYBLOCK Insecticidal Tag" Against Bloodsucking Insects Research. Journal of Pharmaceutical, Biological and Chemical Sciences, vol. 11, issue 3, pp. 112-119.

[22] Pati, P. C. and Bhunya, S. P. (1989). Cytogenetic Effects of Fenvalerate in Mammalian in Vivo Test System. Mutation Research, vol. 222, issue 3, pp. 149-154.

[23] Slaughter, R. L. (2013). Pharmacokinetic Behavior Presents Drug Therapy Challenges. Expert Review of Clinical Pharmacology, vol. 6, issue 6, pp. 627-639.

[24] Ramchandra, A. M., Chacko, B. and Victor, P. J. (2019). Pyrethroid Poisoning. Indian Journal of Critical Care Medicine, vol. 4, pp. 267-271. 